\title{
DESIGN AND EVALUATION OF MECHANICAL PICKING HEAD FOR PEACH FRUITS HARVESTING
}

\author{
HAMAM, A. S., M. E. EL-IRAQI, S. E. EL KHAWAGA AND T. R. AWAIS \\ Agric. Eng. Res. Inst., ARC, Dokki, Giza, Egypt.
}

(Manuscript received 10 July 2011)

\begin{abstract}
The traditional harvesting peach fruits methods using hand hook and hand picking consider the most important problems still facing the peach producers in Egypt due to lower picker productivity and fruit quality. Therefore, two mechanical harvesting prototypes (electrical picking hook and electrical picking holder) were designed and fabricated for picking peach fruits as a simple low cost picking heads that assures having fair fruit quality with minimal damage and evaluating the effect of using it on the picker performance and productivity. The evaluation experiments were carried out during picking peach fruit seasons of 2007 and 2008 at some private peach farms in EL-Arish, North Sinai Governorate and old Meet-Ghamr, Dakhalia Governorate, Egypt.

The obtained results allow us to drawn the following conclusions

- The picker productivity using electrical picking hook was increased by about $(91.32,146.92$, and $46.30 \%$ and saving the total harvesting cost by about $47.73,62.29$ and $41.38 \%$ (as an average percentages for picking Meet Ghamr and Early Grand peach fruits varieties) comparing with electrical picking holder, manual picking hook and hand picking method, respectively.

- Using electrical picking hook gave the lowest percentage of bruised $(3.0 \%)$, damaged fruit percentage $(1.0 \%)$, and the highest value of good quality fruit percentage $96.0 \%$ (extra fancy-Grade I) comparing with other mechanical and traditional harvesting methods under study.

- The authors recommended to locally fabricate and use the electrical picking hook for harvesting peach fruits to increase labor picking productivity and reduce picking cost. In addition to increase the rate of good quality for local and exporting fresh markets, consequently, increasing the net benefit and national income. However, the electrical picking holder still needs some modifications to increase its performance efficiency.
\end{abstract}

\section{INTRODUCTION}

Egypt stands among the largest peach producing countries in the world and occupies the $11^{\text {th }}$ rank in production amongst the $17^{\text {th }}$ producing countries. Egyptian peach has a relative advantages in terms of early ripening and nearness to international importing markets, in addition to the yield, fruit quality and relative low labor cost. Consequently, this creates a unique situation that favors Egypt as a potential exporter for fresh market peach fruits especially to European and Arabic 
Gulf countries in April and May every year due to early ripening of Egyptian peach varieties before other competition countries, therefore, the exported quantities of peach fruits have been generally increasing. For these reasons, in Egypt, the total area of peach fruits was increased from 2.7,000 fed. in 1982 (produced 69000 ton) to 78,494 fed in 2001 (produced 224,183 ton) to 83,703 fed in 2007 (produced 420,273 ton). Peach planting in new reclaimed lands in north of Sinai Governorate (rainy planting) represents about $80 \%$ of the total area of peach fruits in Egypt where the average yield was about 3-4 tons/fed compared to 8-12 tons/fed in irrigated old lands (E. A. S., 2008).

Horsfield et. al. (1972a) studied the optimization of mechanical harvesting procedures for apricots of non-uniform maturity. It was concluded that, the selective tree harvesting was more profitable than hand harvesting but the once-over harvesting method was not as profitable as hand harvesting, especially for large orchards. They stated that a combination of hand harvesting to remove the more mature tip fruits, followed by machine harvesting, might had potential and should be evaluated.

Sims et. al. (1973) described an integrated system of growing, harvesting and handling peaches using growth regulators, a mechanical harvester, and a portable field dumper-sorter capable of applying fungicides, which would make possible to deliver acceptable quality fresh-market peaches. They identified cuts which led to fruit rot development during storage as the most serious problem related to mechanical harvesting. However, encouraging results on mechanical harvesting of peaches for fresh market have been reported by (Kunz et. al., 1975) Bruising due to impacts, which may be manifested internally in the flesh is a major limiting factor for harvest mechanization in fresh-market peaches.

Zocca and Fridly (1977) indicated that the limitations to mechanical harvesting of peach fruits include bruising, variation in fruit maturity, low tree profiles damage tree trunk and limbs from shaker action. However, with proper management of the harvesting operation, clingstone peaches can be successfully harvested mechanically. In 1980 about $35 \%$ of the clingstone peach crop in California was harvested mechanically. Since bruising can be higher in mechanically harvested fruits, they should be processed soon after harvested in order to minimize fresh browning, (Kader, 1980).

Sansavini et. al. (1982) conducted that a mechanical harvesting trial using a mechanical harvester prototype from Bologna University, specially designed and tested for harvesting apricots and prunes. Their tests showed that the use of the 
mechanical harvester resulted in an average loss of $15 \%$ of the fruit, but the harvester offered high working speed, manpower saving, etc.

Kader (1983) studied the influence of the harvesting methods on quality of deciduous tree fruits and his results concluded that the continuing consumer demands for high flavor-quality fresh fruits indicated the need for picking fully ripe fruits, which cannot be mechanically harvested without serious damage. The success of future research efforts in developing mechanical-harvesting systems will require continued cooperation between horticulturists and agricultural engineers. Research by horticulturists should emphasize modification in the production systems of deciduous tree fruits. Research by agriculture engineers should continue to improve fruit detachment and collection systems to minimize mechanical injuries to fruits and trees.

Sansavini and Costa (1986) conducted research on mechanical harvesting and pruning of apricot trees. They found that manual harvesting of the bigger and more appealing fruits was necessary for the fresh market and with the remaining ones could be harvested by shaker for the processing industry.

Zocca et. al. (1991) described technical data and performance of a fully automated fruit harvester. The single unit fully automatic fruit harvester featured ultrasound, magnetic and mechanical sensors fed input data to a proportional linear controller and hydraulic system that, sequentially, ran all harvesting operations, including trunk positioning. Only one person was needed to operate the unit and over 80 trees/h can be harvested.

Sarig (1993) concluded that mechanization of the fruits harvesting, and primarily of those that are destined for the fresh market, is still a manual task and is highly desirable in many countries due to the decrease in seasonal labor availability. Some of the technology exists for harvesting fruit intended for processing, but its utilization for soft, fresh fruit is limited, because of the excessive mechanical damage to the fruit during mechanical harvesting. Also, all mechanical harvesting today is based on once-over harvesting with no provisions for selective harvesting a quite common requirement for many fruit crops.

Horvath and Sitkei (2001) proposed a new tree model which analyzed three different kinds of trunk motion. Based on acceleration measurements in the soil body, a new mass component was included, in addition to the common mass components. An analysis of dynamics and power requirement of the system has shown that the elastic deformation of the trunk will continuously be higher as attachment height increases, resulting in a significant decrease in the net power requirement.

Erdogan et. al. (2003) designed and constructed an inertia type limb shaker hydraulically, powered and driven by the tractor power take-off, for the mechanical 
harvesting of apricots. In the tests, the limbs were shaken at 20, 30, 40, 50 and 60 $\mathrm{mm}$ amplitude of the connecting rod attached to the crankshaft and 10,15 and $20 \mathrm{~Hz}$ frequencies for optimum shaking time. The shaking time, frequency and amplitude for a limb were found as $5 \mathrm{~s}, 15 \mathrm{~Hz}$, and $40 \mathrm{~mm}$, respectively. Limb position, limb length and tree size affected the fruit removal percentage at the $5 \%$ significance level. The least fruit damage was obtained with the plastic canvas catching surface.

Sanders (2005) reported that the most difficult aspect is the selection and removal of the individual pieces of fruit from the tree. None of the currently available mechanical harvesting systems have been able to fully replace the flexibility and fruit selection abilities of manual pickers. And most of them only have crop selection capacity. These harvesters are designed to remove all of the current season fruit from the tree during the first picking operation. Picking the fruit in one operation has the disadvantage that it results in a proportion of the fruit picked not being of optimum quality, because some of the less mature fruit on the tree will not have reached optimum quality and some of the more mature fruit will have begun to deteriorate. Hence, the maximum achievable financial return is heavily dependent upon the fruit quality distribution on the day of picking.

Polat et. al. (2007) used an inertia type limb shaker, hydraulically powered and driven by the tractor power take-off, for mechanical harvesting of pistachio nuts. In the tests the limbs of trees were shaken at 40,50, $60 \mathrm{~mm}$ amplitude of the connecting rod attached to the crank-shaft and 10,15, $20 \mathrm{~Hz}$ frequencies. Shaking time was $10 \mathrm{~s}$ for all of the frequency and amplitude tests. Their results concluded that, maximum fruit removal $(100 \%)$ was achieved by operating the shaker at amplitude of $60 \mathrm{~mm}$ and a frequency of $20 \mathrm{~Hz}$. Tree structure is the most significant factor influencing the success with mechanical harvesting of fruits.

Torregrosa et. al., (2008) designed and constructed catching systems to pick the peaches detached from the trees by shaking with hand-held shakers. The experiments were carried out on a crop of peaches cv. Caterina. Three catching systems were tested: A) a pair of canvases, B) a catching trailer with extendable flat planes, and C) a pair of canvases with direct discharge to boxes. Their results indicated that fruit detachment percentage with the hand-held shakers ranged between $83 \%$ and $95 \%$. Less than $2.4 \%$ of the fruits were severely injured. Harvesting rates per operator increased from $100 \mathrm{~kg} / \mathrm{h}$ with hand harvesting to nearly $200 \mathrm{~kg} / \mathrm{h}$ with systems A and B and to more than $300 \mathrm{~kg} / \mathrm{h}$ with system C. System C was also tested to harvest fresh market peaches cv. Tardivel, but $13 \%$ of the fruits were damaged to some extent (severe and slight) and this was not acceptable for the producers. 


\section{Problem statement}

Nowadays, Several of the mechanical harvesters have been able to reduce the labor requirement and greatly increase the picking rate achieved by manual pickers, in addition to overcome the shortage of labor supply for hand harvesting. From this stand point, this research had been directed towards finding an efficient mechanized picking method to harvest peach fruits for fresh market, reducing labor requirements as well as maximizing manual picking productivity and fruit quality in order to minimize the total harvesting costs and increase the exporting peach fruits rates. Therefore, the aim of the present study is to design and fabricate a small scale prototype of peach picking head as a simple low cost picking heads that assures having fair fruit quality with minimal damage and then evaluate the effect of using it on the picker productivity.

\section{MATERIALS AND METHODS}

\section{1- Materials}

In this study, two designed prototypes of harvesting tools namely electrical picking hook and electrical picking holder were evaluated under field harvesting conditions. The fabrication of these prototypes was carried out at the some private workshop in El-Mansoura and Damnhour cities, Egypt, in 2007. The construction and the main components of both types of harvesting heads could be explained as follows:

\section{1-1 Peach electrical picking hook}

The prototype of the designed peach electrical picking hook was constructed from the following main parts as indicated in Fig. (1).

1- A telescopic carrier consists of two hallow aluminum pipes $3 \mathrm{~m}$ length for each. The upper one $(\phi=16 \mathrm{~mm})$ is inserted into the lower one $(\phi=20 \mathrm{~mm})$ to adjust the height of peach electrical picking hook.

2- Picking mechanism consists of a linear Dc motor, $12 \mathrm{v}-70$ Ah, hook shaft, retrain spring, picker shaft guide and picker hook. The DC motor is fixed on the upper end of the telescopic carrier, while the hook shaft is fixed inside the magnetic coil of the DC motor to create magnetic field suitable for attracting down the hook shaft after connecting the direct current to it. The retrain spring was used to retrain hook shaft to its start point again after ending its down attract stroke. The picker hook is fixed on the upper end of the hook shaft, its shape like $v$ letter, while the picker shaft guide used to prevent the picker hook from exiting out and rotating in magnetic coil during picking operation. 
3- Fruits collecting mechanism consists of fruit receiving/transporting tube and fruit collecting basket. The upper end of fruits receiving tube $(\phi=25 \mathrm{~cm})$ is fixed on the telescopic carrier under the picker hook with about $20 \mathrm{~cm}$ to receive and transport the picked fruits to the mobile fruit collecting basket.

4- DC source and operation circuit, a battery (12v-70 Ah ) was used as DC source to operate the linear DC motor through electrical wires passing inside pipes of telescopic carrier, while the operation switch was fixed on the lower pipe of the telescopic carrier in a suit place for operator hand .

Working theory: The operator (picker) selected the mature peach fruit on the tree and detected it by the picking head by adjusting the two wings of picker hook around the peach fruit twig, then switched on to connect the DC current for magnetic coil to create a magnetic field which pull the hook shaft to the down side. Consequently, the picker hook detaches the peach fruit and dropped it to the fruit receiving tube. After filling the mobile basket with fruits, the operator move and empty it in the fruit boxes.

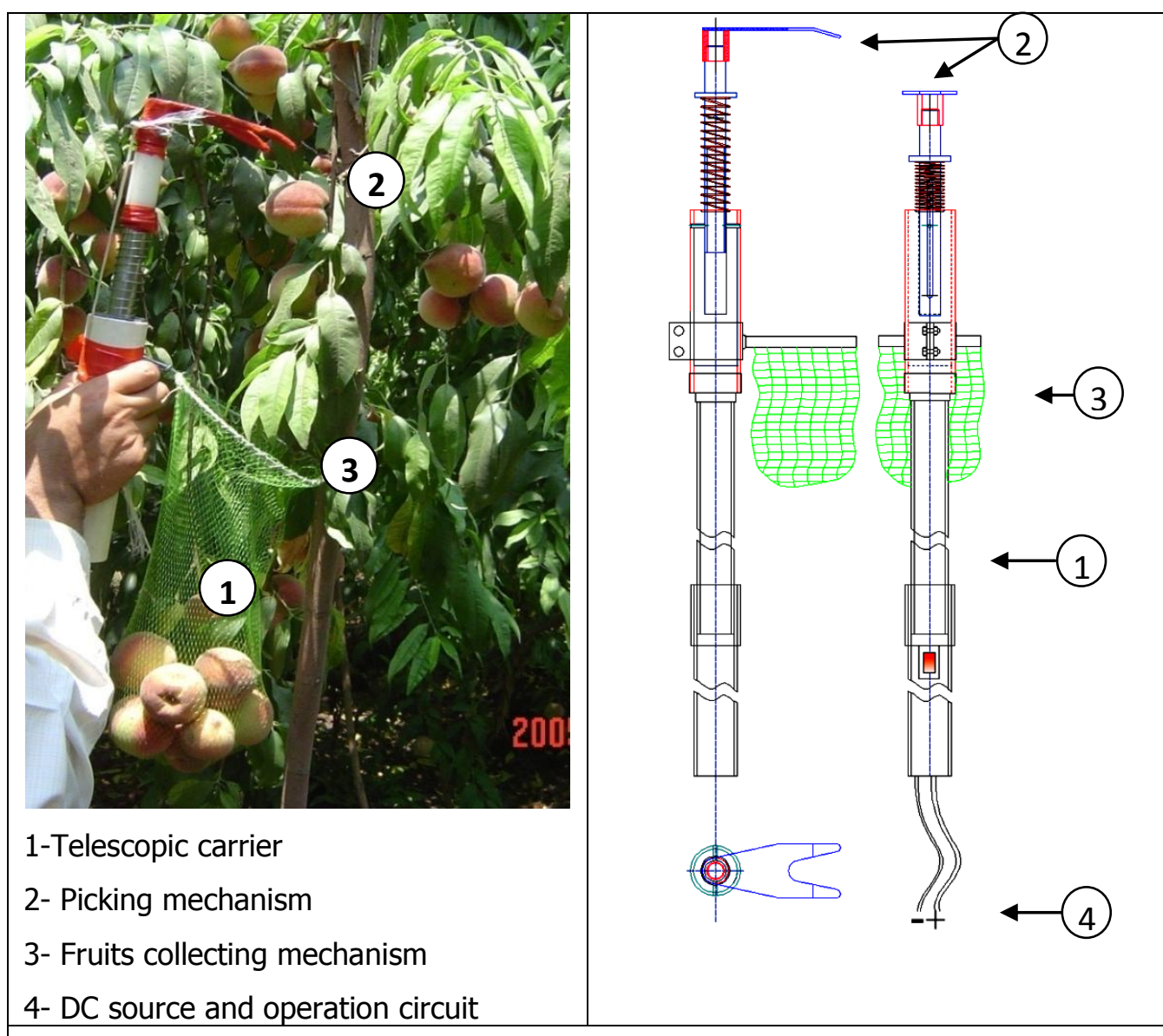

Fig. 1. Main components and schematic diagram of electrical picking hook for peach fruits. 


\section{1-2 Peach electrical picking holder}

The main components of the peach electrical picking holder prototype are shown in Fig. (2):

1- A telescopic carrier consists of two hallow aluminum pipes $3 \mathrm{~m}$ length for each. The upper one $(\phi=16 \mathrm{~mm})$ is inserted into the lower one $(\phi=25 \mathrm{~mm})$ to adjust the height of peach electrical picking hook.

2- Picking mechanism consists of a linear Dc motor, 12 v - 70 Ah, holder shaft, holder cam, retrain spring, picker shaft guide and holder hands. The DC motor is fixed on the upper end of the telescopic carrier, while the holder shaft is fixed inside the magnetic coil of the DC motor to create magnetic field suitable for attracting down holder shaft after connecting the direct current to it. The retrain spring used to reopen holder hands again after ending its stroke to catch another peach fruit. The two holder hands are fixed on the upper end of the holder shaft. The shape of the holder hand almost same spoon. The inner surface of holder hand (spoon) is covered by rubber material. The holder cam used to make the catching fruit action by holder hands during attracting the holder shaft to the down side.

3- Fruits collecting mechanism consists of fruit receiving/transporting tube and fruit collecting basket. The upper end of fruits receiving tube $(\phi=25 \mathrm{~cm})$ is fixed on the telescopic carrier under the holder with about $25 \mathrm{~cm}$ to receive and transport the picked fruits to the mobile fruit collecting basket.

4- DC source and operation circuit, a battery ( $12 \mathrm{v}-70 \mathrm{Ah})$ was used as DC source to operate the linear DC motor through some electrical wires passing inside pipes of telescopic carrier, while the operation switch was fixed on the lower pipe of the telescopic carrier in a suit place for operator hand.

Working theory: This mechanism was designed to simulate the same hand picking action of peach fruits by catching and pulling it down side to detach it from its twig. The operator select the matured peach fruits to be picked from fruit distribution layers on the peach trees and positioning the electrical picking holder to it, then the operator switched on to connect the magnetic coil with the battery, therefore the picker holder catching the peach fruit and moves down side rapidly in the same time to detach it from its twig and positioning it to fruit collecting basket as shown in Fig. (2). 


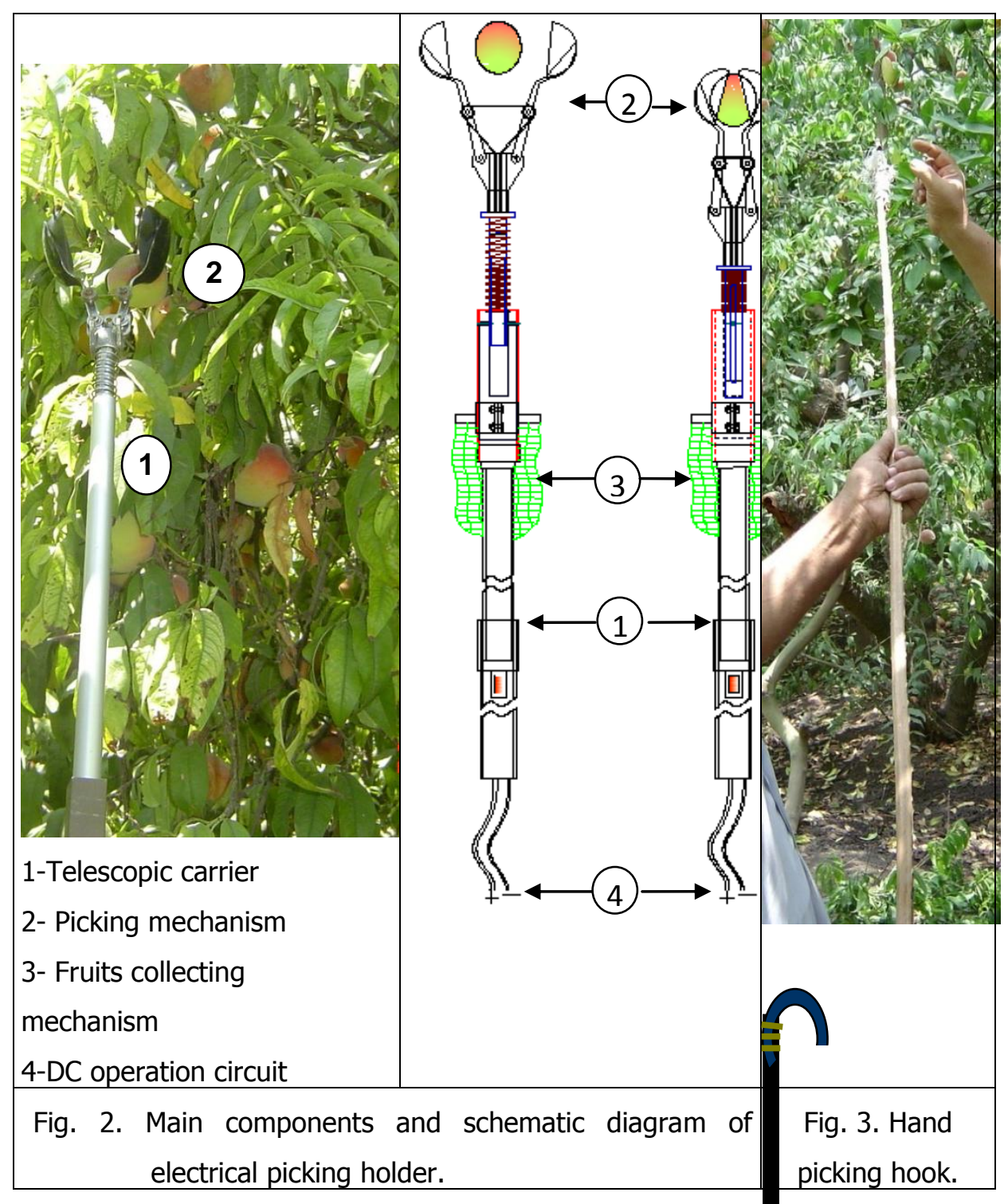

\section{1-3 Peach hand picking hook}

A Peach hand (traditional) picking hook is consists of plants (about 2.5-3m length, 3-4 cm diameter) and about 3 $=1.5 \mathrm{~cm}$ ) was curved and fixed at the upper end of long stick as picker catch this traditional hook and pulling matured peach ng stick from some $\mathrm{cm}$ of steel bar $(\phi$ hown in Fig. (3). The shaking its tree branches. The picked fruits by hand hook fruits or hitting and ground from different fruit distribution layer heights, therefore another labor collect these fruits in fruit basket

\section{2- Performance test and evaluation}

Two experiments were carried out to evaluate the perf rmance of designed picking peach prototypes. The first one was done to study the ef ect of using designed electrical picking hook and holder as a mechanical methods fo picking Early Grand and Meet Ghamr peach fruit varieties comparing with hand $\mathrm{h}$ bk and hand picking 
methods as a traditional peach picking methods. The second experiment was done to study the effect of fruit height on the tree and using five different skill pickers (P1 to P5) on the picker productivity to pick Meet Ghamr peach fruits from upper and lower parts of fruit distribution layers on the peach trees by mechanical and manual picking methods under study. Therefore, the distribution fruit layers were divided into two parts. The lower part includes the $1^{\text {st }}$ and $2^{\text {nd }}$ fruit distribution layers while the upper part includes the $3^{\text {rd }}$ and $4^{\text {th }}$ fruit distribution layers. The evaluation experiments were carried out during picking peach fruit seasons of 2007 and 2008 at some private peach farms in new reclaimed (rainy) lands, EL-Arish, North Sinai Governorate and old (irrigated) lands, Meet-Ghamr, Dakhalia Governorate, Egypt.

\section{3- Measurements}

\section{3-1 Peach fruit properties}

The physical properties includes fruit dimensions (length $\&$ diameter), mass and volume. While, the mechanical properties includes fruit penetration resistance and fruit picking force were measured for both peach fruit varieties under study (Early Grand and Meet Ghamr).

\section{3-2 Peach tree characteristics}

The characteristics of peach tree canopy that affect on the performance evaluation of the designed peach picking tools were measured and the average values were calculated. The measuring characteristics includes, tree heights/diameter,

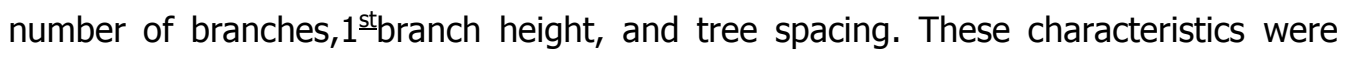
measured for Early Grand and Meet Ghamr peach tree varieties.

\section{3-3 Performance measurements}

The performance measurements such as, total picking time, picker productivity (ton/h) and fruit quality were measured during picking Early Grand and Meet Ghamr peach fruit varieties using designed mechanical peach picking tools under study comparing with other traditional peach picking methods (hand picking and manual hook).

\section{3-3-1 Total picking time and picker productivity}

The total picking time required for selecting/detecting the mature fruit and catching by hook/holder, detaching it and collecting in the fruit basket/box was measured and recorded using five different pickers (labors) with both types of the designed peach picking heads to calculate the average value of picker productivity (ton/h) comparing with peach traditional picking methods. Also, the total picking time includes the lost time for moving picking heads between peach trees and branches, in addition to the required time to empty full fruit basket. 


\section{3-3-2 Quality of harvested peach fruits}

The quality of picked peach fruits was evaluated by calculating the fruits percentage having visible mechanical damage due to fall fruits out of receiving tube/basket or cutting by picking head parts. However, the invisible mechanical damage estimated by storing samples of fruits by mechanical and manual picking methods for a period of one week under the room temperature. The reaching to the validity period of 5 days without deterioration was taken as an indicator to calculate the percentage of good fruit quality (extra fancy-Grade I). Five Fruit samples (each samples about 20 fruits) were randomly collected from fruit basket for each picking method under study.

\section{3-3-2 Estimation harvesting cost}

The harvesting cost (LE/h and LE/ton) was estimated during picking Early Grand and Meet Ghamr peach fruit varieties using designed electrical picking hook and holder as a mechanical methods comparing with hand hook and hand picking methods as a traditional peach picking methods. The following assumption bases were taken into consideration during estimation harvesting cost: picker wage (4 LE /h), collecting labor wage (3 LE /h), electrical picking hook or holder and its accessories cost (1000 LE), picking head life (3 years with 200 yearly working hours), one labor for mechanical method and two labors for traditional method (one for picking and other for collecting fruits).

\section{RESULTS AND DISCUSSION}

\section{1- Physical and mechanical properties of peach fruits}

The minimum, maximum, average and standard deviation (SD) values of the physical and mechanical properties of the Early-Grand and Meet Ghamr peach fruit varieties (El-Arish and Meet-Ghamr regions, respectively) were measured, calculated and summarized in Table (1). 
Table 1. Physical and mechanical properties for peach fruits.

\begin{tabular}{|c|c|c|c|c|c|c|}
\hline Peach Variety & Measurements & Min. & Max. & Average & SD. & C.V\% \\
\hline \multirow{6}{*}{ Early Grand } & Length, mm & 51.00 & 69.10 & 62.43 & 5.09 & 8.15 \\
\hline & Diameter, $\mathrm{mm}$ & 55.10 & 73.50 & 61.15 & 5.23 & 8.56 \\
\hline & Mass, $\mathrm{g}$ & 75.00 & 160.0 & 107.40 & 23.32 & 21.71 \\
\hline & Volume, $\mathrm{cm}^{3}$ & 83.5 & 127.2 & 96.00 & 14.6 & 15.21 \\
\hline & Penetration resistance, $\mathrm{N}$ & 1.3 & 17.2 & 7.89 & 6.23 & 78.96 \\
\hline & Picking force, $\mathrm{N}$ & 11.00 & 35.03 & 16.67 & 9.64 & 57.82 \\
\hline \multirow{6}{*}{ Meet Ghamr } & Length, $\mathrm{mm}$ & 5.10 & 6.70 & 5.84 & 0.49 & 8.38 \\
\hline & Diameter, $\mathrm{mm}$ & 4.85 & 6.80 & 5.61 & 0.54 & 10.47 \\
\hline & Mass, $\mathrm{g}$ & 61.58 & 158.96 & 91.88 & 30.05 & 32.71 \\
\hline & Volume, $\mathrm{cm}^{3}$ & 45.50 & 185.0 & 98.00 & 39.31 & 40.11 \\
\hline & Penetration resistance, $\mathrm{N}$ & 4.45 & 22.25 & 8.72 & 5.53 & 69.51 \\
\hline & Picking force, $\mathrm{N}$ & 0.10 & 14.70 & 4.72 & 5.96 & 126.27 \\
\hline
\end{tabular}

The obtained results indicated that the average values of the length, diameter, volume and mass of the Early-Grand peach variety were found to be higher than obtained for the Meet-Ghamr peach fruits. However, the average values of penetration resistance for Meet Ghamr peach variety $(8.72 \mathrm{~N}$ ) higher than that (7.89 N) for Early Grand peach variety. Meanwhile, the average values of the picking force for Early Grand peach fruits $16.67 \mathrm{~N}$ ) were extremely higher than that obtained (4.72 N) for Meet Ghamr peach fruits.

\section{2- Peach tree characteristics}

The characteristics of peach tree canopy and fruit distribution percentage on the tree layers were measured and calculated for Early Grand and Meet Ghamr peach varieties. The obtained results indicated that there are significant differences in the average values of the tree characteristics for both varieties under study as illustrated in Fig. (4-a,b).The average values of tree height $(2.25 \mathrm{~m})$, tree canopy diameter $(3.25 \mathrm{~m})$ and tree spacing $(4.0 \times 4.0 \mathrm{~m})$ were obtained for Early Grand peach variety. However, the corresponding values for Meet Ghamr peach tree variety were $4.0 \mathrm{~m}$ tree height, $3.20 \mathrm{~m}$ tree canopy diameter and $3.0 \times 3.5 \mathrm{~m}$ tree spacing. 


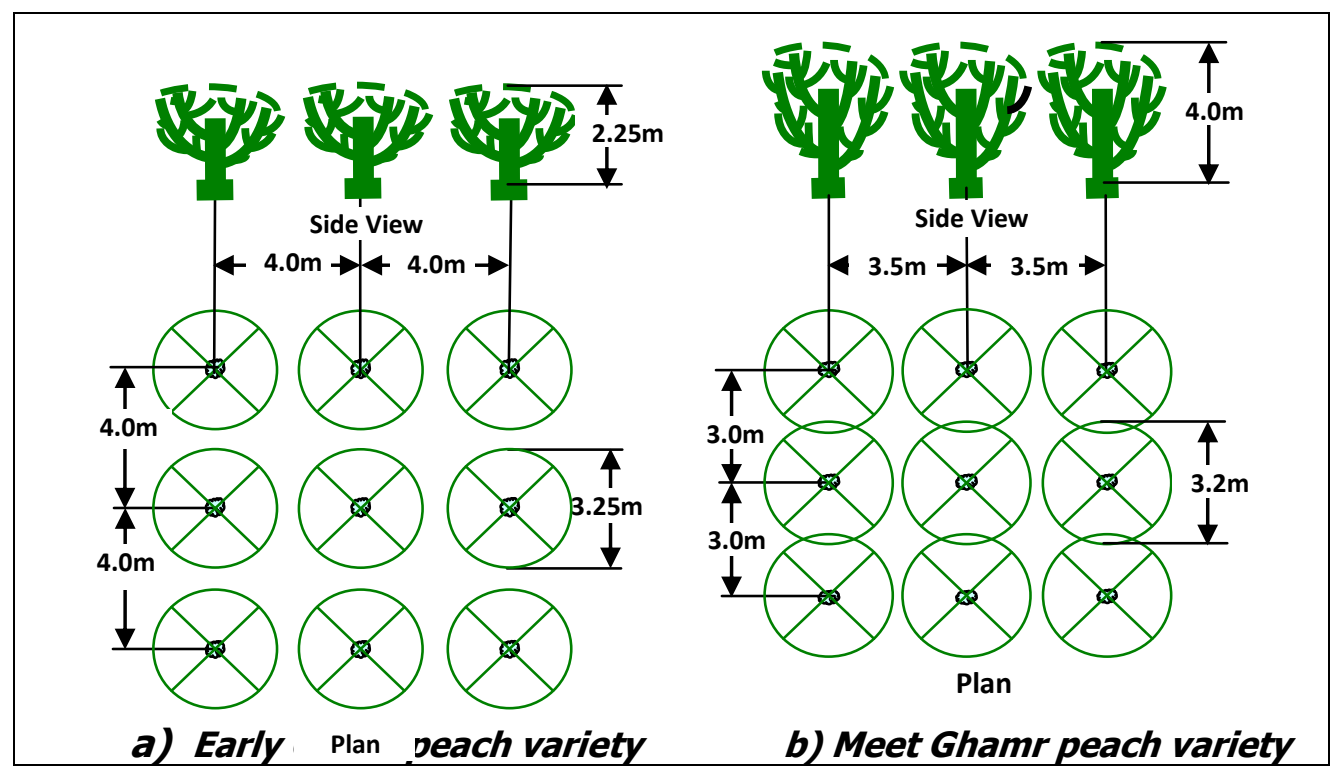

Fig. 4. The characteristics of peach tree canopy.

The $1^{\text {st }}$ main branch starts at average height of $0.40 \mathrm{~m}$ from the ground surface with 4-5 main branches on the Early Grand peach tree. However, the $1^{\text {st }}$ main branch starts at average height of $0.5 \mathrm{~m}$ from ground surface with 4 main branches on the Meet Ghamr peach tree. The fruits distribution of Early Grand peach variety was concentration on the outer circumference of the tree on the $1^{\text {st }}$ and $2^{\text {nd }}$ layers from ground surface. While the upper layer ( $3^{\text {rd }}$ layer) contain the lowest percentage of fruit distribution as shown in Fig. (5-a). The percentage of fruit distribution on the Meet Ghamr trees were concentrated at the outer circumference of the tree on $2^{\text {nd }}$ and $3^{\text {rd }}$ layers from ground surface. While the lowest percentage of fruit distribution was found on the $1^{\text {st }}$ layer of the tree as indicated in Fig.(5-b).

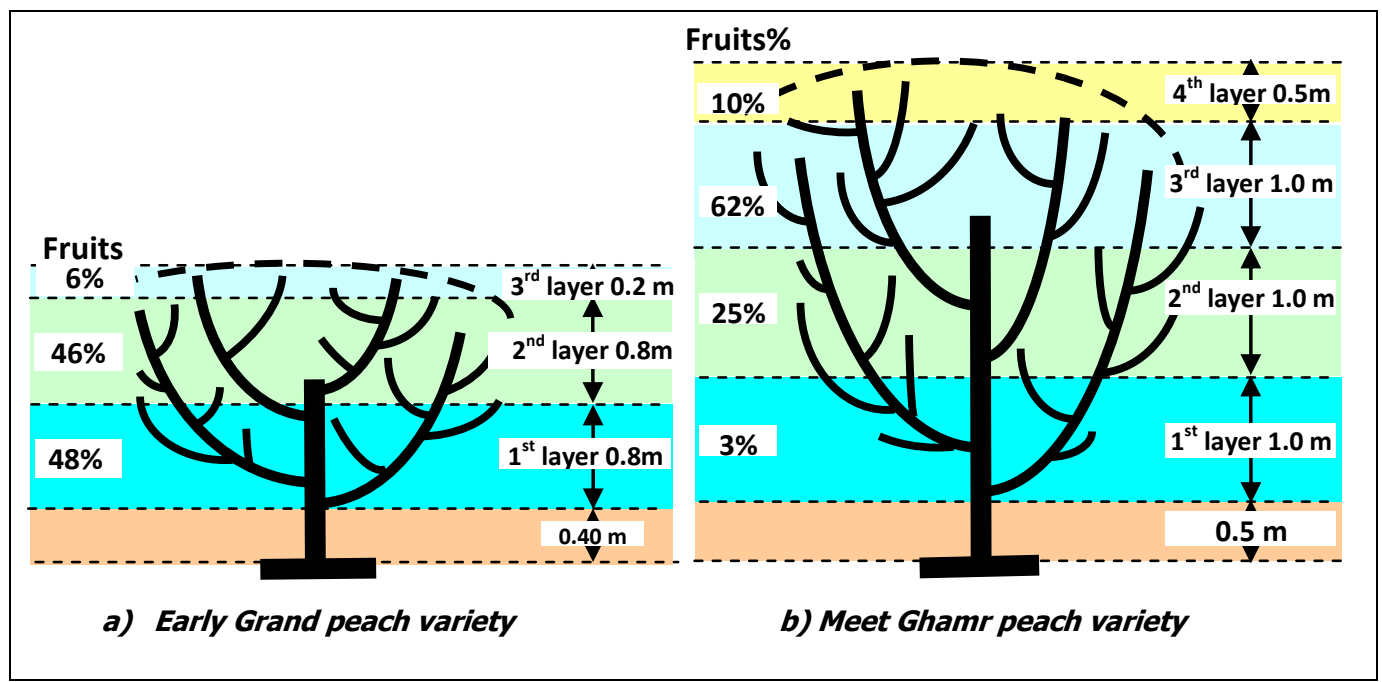

Fig. 5. The percentages of fruits distribution layers on the peach trees. 


\section{3-Performance evaluation}

\section{3-1-Picker productivity}

The average values of picker productivity(ton/h) was estimated using designed mechanical and traditional picking methods for picking Early Grand and Meet Ghamr peach fruit varieties. The obtained results are illustrated in Fig. (6) and indicated that, using electrical picking hook gave the highest picker productivity $(0.194 \& 0.211$ ton/h) comparing with other picking methods. However, using hand picking method gave $0.129 \& 0.148$ ton/h followed by the productivity of picking holder $(0.102 \&$ 0.110 ton/h) and productivity of the hand hook $(0.078 \& 0.086$ ton/h) during picking Early Grand and Meet Ghamr peach fruit varieties, respectively.

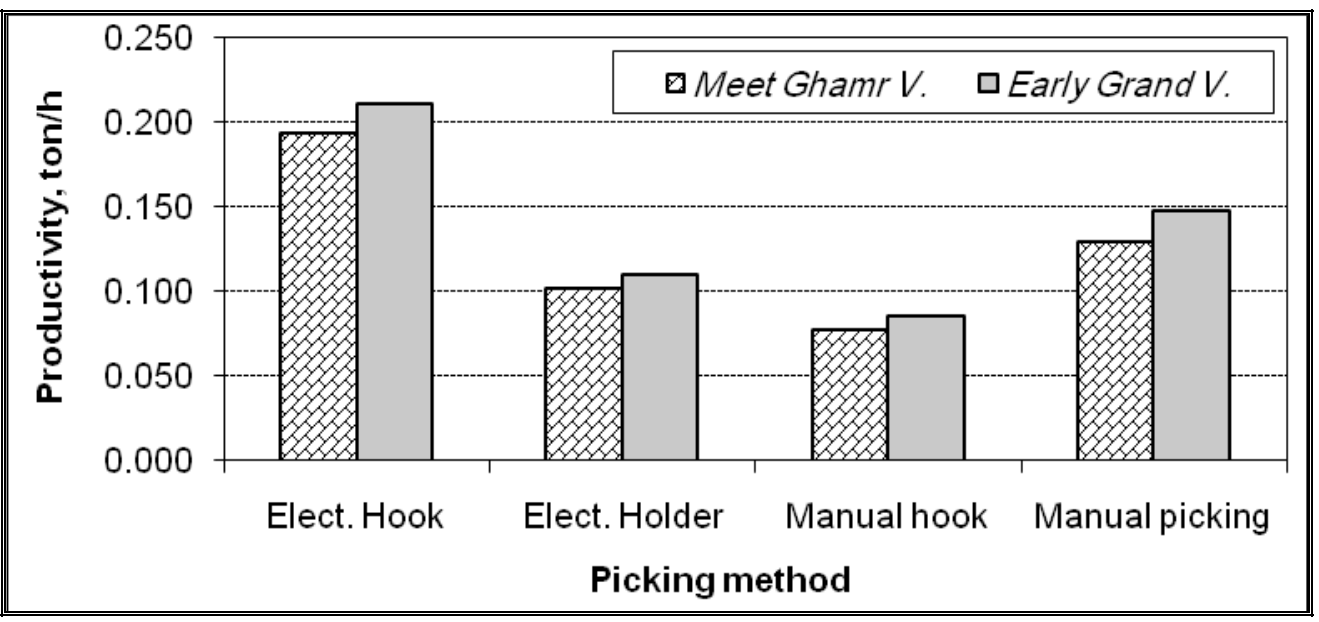

Fig. 6. Effect of using designed mechanical heads comparing with traditional methods for picking of Early Grand and Meet Ghamr peach fruits varieties.

The picker productivity using electrical picking hook was increased by about (90.70, 148.05, and 49.91\% comparing with labor productivity using electrical picking holder, hand picking hook and hand picking method, respectively for picking Meet Ghamr peach fruits variety. However, the corresponding values for Early Grand peach fruits variety were about $91.94,145.78$ and $47.70 \%$, respectively. These results may be due to saving the required time for collecting fruits from ground surface, which increased the picker productivity comparing with traditional picking methods. Meanwhile, it could be indicated that, the picker productivity was increased during picking Early Grand peach fruits variety by $8.29,7.70,9.13$ and $12.7 \%$ than Meet Ghamr peach fruits variety using electrical picking hook, electrical picking holder, hand picking hook and hand picking, respectively. These results may be due to lower values of Early Grand peach tree height's and canopy volume than Meet Ghamr peach trees, which decreasing the lost time during picking operations. 
Regarding to the effect of fruit height on the tree and using different skill pickers (P1 to P5) on the picker productivity for picking Meet Ghamr peach fruits from lower and upper parts of peach tree using mechanical and traditional picking methods. One can say, the picker productivity values were various from picker to other according to the his ability and skill for using the picking head as shown in Fig. (7) using any given mechanical and manual picking method. Also, it could be concluded that, the picker productivity values were increased during picking peach fruits from lower part than upper part for any given picker and picking method. However, the highest average value $(61.60 \%)$ of increment percentage in picker productivity between lower and upper tree parts was achieved by using hand picking method comparing with $37.24,49.19$ and $39.43 \%$ when using electrical picking hook, electrical picking holder and hand picking hook, respectively.
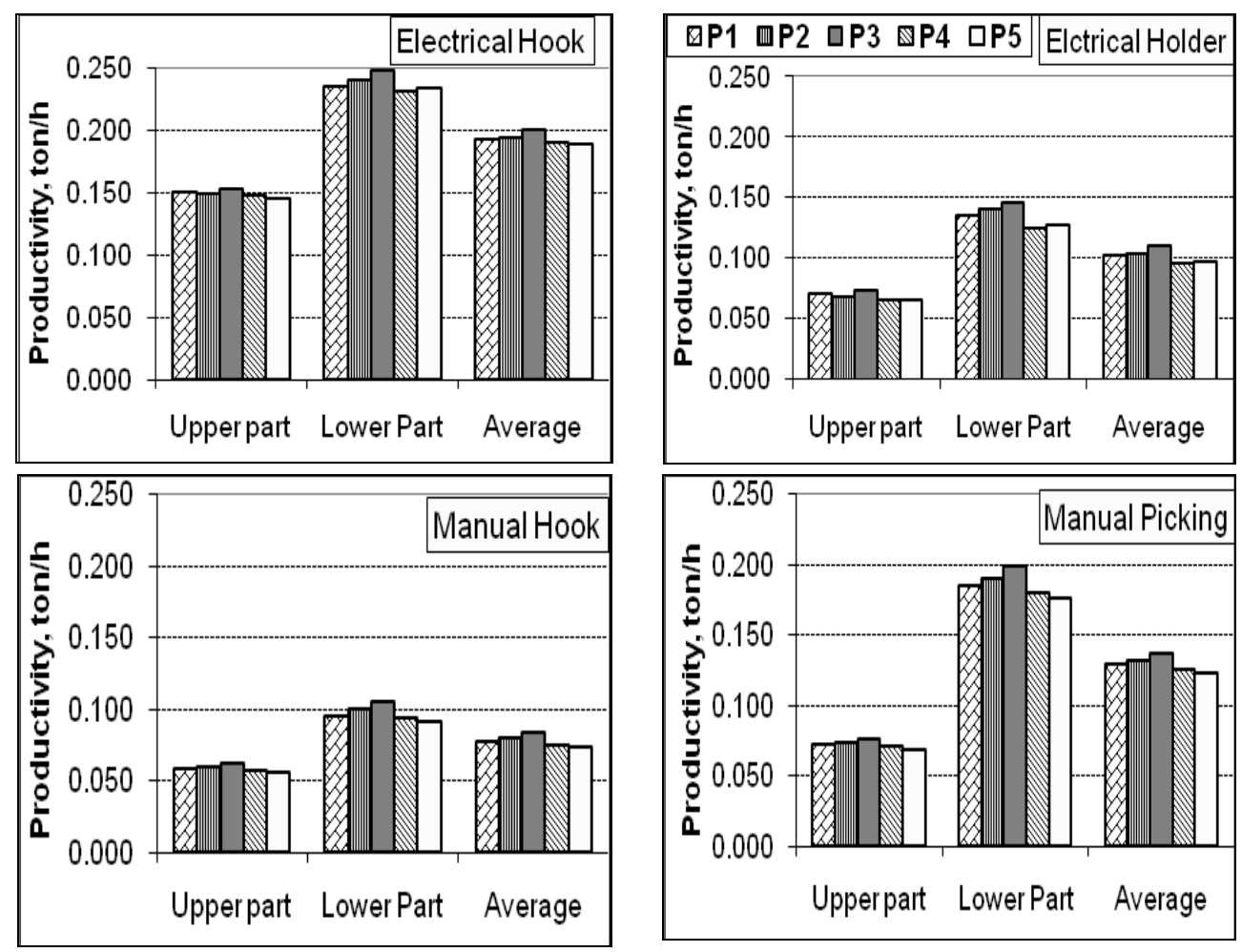

Fig. 7. Effect of using different pickers (P1 to P5) for picking peach fruits from lower and upper parts of peach tree on the picker productivity.

\section{3-2 Picked fruit quality}

The effect of using the designed electrical picking hook and holder on the picked fruits quality were measured and estimated in comparison with the effect of the traditional picking methods. The visible mechanical damage percentages due to bruised fruits which falling on the ground or cutting by picking head parts, fruit 
validity periods and the percentages of good fruit quality using mechanical and traditional picking methods were estimated and summarized in Table (2). From these results it could be concluded that using electrical picking hook gave the lowest percentage of bruised $(3.0 \%)$, damaged fruit percentage $(1.0 \%)$, the highest validity period ( 5 days) with the highest value of good quality fruit percentage $96.0 \%$ (extra fancy -grade I). These results means that using the electrical picking hook increasing the rate of good fruit quality for local and exporting fresh markets, consequently increasing the net benefit and national income. However, using manual hook gave the highest percentage of bruised fruit $(81.0 \%)$, damaged fruit percentage $(7.0 \%)$ and the lowest validity period (1day) with lowest percentages of good quality $(12.0 \%)$ comparing with electrical picking holder, manual picking hook and hand picking method. These results may be due to the impact action for falling fruits on the ground especially the matured fruit from $3^{\text {rd }}$ and $4^{\text {th }}$ layers.

Table 2. Effect of using mechanical and manual harvesting method on the peach fruits quality.

\begin{tabular}{|c|c|c|c|c|}
\hline $\begin{array}{c}\text { Picking } \\
\text { method }\end{array}$ & $\begin{array}{c}\text { Bruised } \\
\text { (Falling) fruit, } \\
\text { \% }\end{array}$ & $\begin{array}{c}\text { Damaged } \\
\text { fruit, \% }\end{array}$ & $\begin{array}{c}\text { Av. } \\
\text { Validity } \\
\text { period }\end{array}$ & $\begin{array}{c}\text { Good fruits } \\
\text { (Extra } \\
\text { fancy),\% }\end{array}$ \\
\hline Electrical hook & 3.0 & 1.0 & 5 days & 96 \\
\hline Electrical holder & 11.0 & 3.0 & 3 days & 86 \\
\hline Hand hook & 81.0 & 7.0 & 1 day & 12 \\
\hline Hand picking & 4.0 & 2.0 & 5 days & 94 \\
\hline
\end{tabular}

\section{4- Estimation harvesting cost}

The average values of estimation harvesting cost $(L E / h)$ were found to be 6 and $7 \mathrm{LE} / \mathrm{h}$ for using mechanical and traditional peach picking methods, respectively. Also, the average values of estimation harvesting cost (LE/ton) were 29.67, 56.75, 85.48 and 50.69 LE/ton when using electrical picking hook, electrical picking holder, hand hook and hand picking method, respectively for picking peach fruit varieties under study. From these results it could be reported that using electrical picking hook for picking peach fruits saving harvesting cost by about 47.73, 65.29 and $41.38 \%$ comparing with electrical picking holder, hand hook and hand picking methods, respectively.

\section{Conclusions and recommendations}

- The picker productivity using electrical picking hook was increased by about (91.32, 146.92, and $46.30 \%$ and saving the total harvesting cost by about 47.73 , 
62.29 and $41.38 \%$ (as an average percentages) comparing with electrical picking holder, manual picking hook and hand picking method, respectively for picking Meet Ghamr and Early Grand peach fruits varieties.

- Using electrical picking hook gave the lowest percentage of bruised (3.0\%), damaged fruit percentage $(1.0 \%)$,the highest validity period (5 days) and the highest value of good quality fruit percentage $96.0 \%$ (extra fancy-grade I) comparing with other mechanical and traditional harvesting methods under study.

- The authors recommended to locally fabricate and use the electrical picking hook for harvesting peach fruits to increase labor picking productivity and reduce picking cost. In addition to increase the rate of good quality for local and exporting fresh markets, consequently, increasing the net benefit and national income. However, the electrical picking holder still needs some modifications to increase its picking productivity decrease the percentage of falling fruits out its fruit basket.

\section{REFERENCES}

1. E. A. S. 2008. Economic Affairs Sector, Ministry of Agric. and Land reclamation, A.R.E.

2. Erdogan, D.; M. Guner, E. Dursun and I. Gezer. 2003. Mechanical harvesting of apricots. Biosystems Engineering, 85(1), 19-28.

3. Horsfield B.C.; R.B. Fridley and L.L. Claypool. 1972a. Optimum mechanical harvesting procedures for apricots of non-uniform maturity. Transactions of the ASAE, 15(5): 878-882.

4. Horvath E. and G. Sitkei. 2001. Energy consumption of selected tree shakers under different operational conditions. Journal of Agricultural Engineering Research, 80(2): 191-199.

5. Kader, A. A. 1980. Brown discoloration of clingstone peaches. Cling peach quart. 16(1):12-13.

6. Kader, A. A. 1983. Influence of the harvesting methods on quality of deciduous tree fruits. Hortscience, vol. 18(4):409-411.

7. Kunze, O. R.; W. H. Aldred and B. C. Reeder. 1975. Bruising characteristics of peaches related to mechanical harvesting. Trans. Amer. Soc. Agric. Eng.18:939941,945 .

8. Polat, R.I. Gezer; M. Guner; E. Dursum; D. Erdogan and H. C. Bilim. 2007. Mechanical harvesting of pistachio nuts. Journal of food engineering 79: 1131-1135.

9. Sanders, K. F. 2005. Orange Harvesting Systems Review. Bio-systems Engineering, Power and Machinery, 90 (2): 115-125. 
10. Sansavini S. and G. Costa. 1986. Mechanical harvesting and pruning of apricot trees. International Society for Horticultural Science, Second International Workshop on Apricot Culture and Decline, Davis, CA, 10-20 August, pp 179-190.

11. Sansavini S., G. Costa; M. Grandi and U. Lunati. 1982. Performance and suitability for mechanical harvesting of processing apricots: a comparison of six cultivars two training systems and prune inter stock. Symposium on Apricot Culture and Decline, Bucharest, Romania, 16-21 July, pp 364-374.

12. Sarig, Y. 1993. Robotics of fruit harvesting: A State of the Art Review. J. Agric. Eng. Res. 54:256-280.

13. Sims T., J. Webb; C. Hood and J. Gambrel. 1973. Quality of fresh market peaches subjected to a mechanical harvesting and field handling grading system. J. Amer. Soc. Hortscience 98:253-256.

14. Torregrosa, A.; B. Martín, J. García Brunton and J. J. Bernad. 2008. Mechanical Harvesting of Processed Peaches. Applied Engineering in Agriculture Vol. 24(6): 723-729 (American Society of Agricultural and Biological Engineers ).

15. Zocca, A. and R. B. Fridley. 1977. Mechanical harvesting of clingstone peaches. J. Agric. Eng. Res. 22:247-257

16. Zocca, A., F. Malaguti; G. Cristoferi and O. Facini. 1991. Technical data and performance of a fully automated fruit harvester. International winter meeting of the American society of agricultural engineers (pp. 1-13), December 17-20, Chicago, IL, USA. 


\section{تصميم وتقييم نماذج آلية لحصاد ثمار الخوخ}

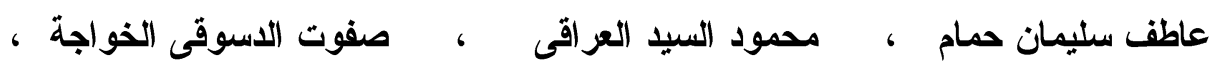

\section{طاهر رشاد عويس}

$$
\text { معهد بحوث الهنسة الزراعية - مركز البحوث الزراعية - دقى - جيزة - دصر • }
$$

تعتبر مصر من الدول الكبرى المنتجة لمحصول الخوخ ورغم ذلك ماز الت الطرق التقليدية المتبعة فى إتمام عملية قطف ثمار الخوخ بالأيدي أو استخدام الخطاف أحد أهم المشاكل التى تو اجه الها

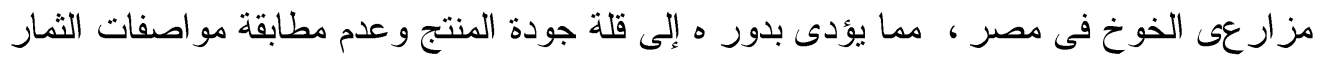

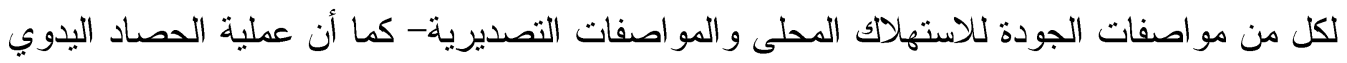

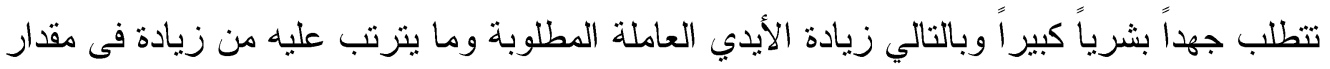

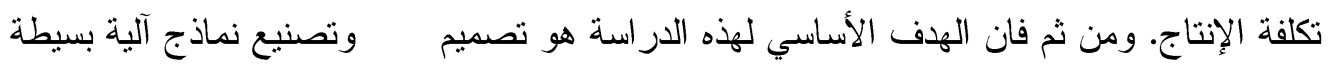

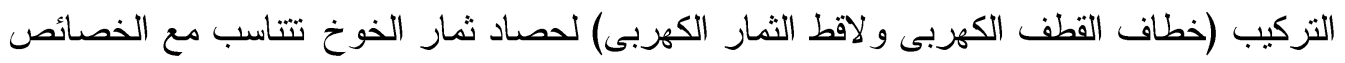

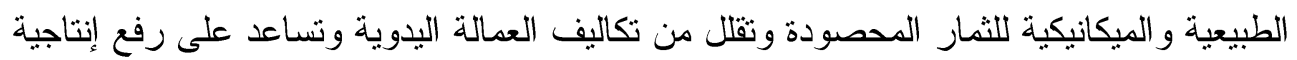

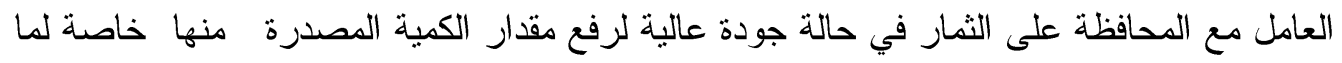

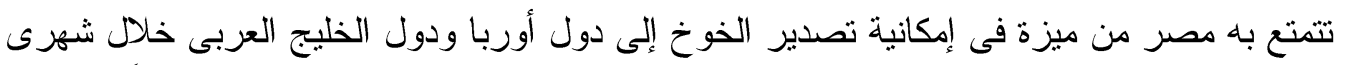

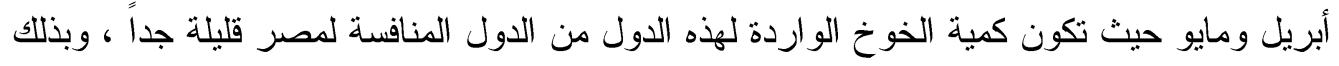

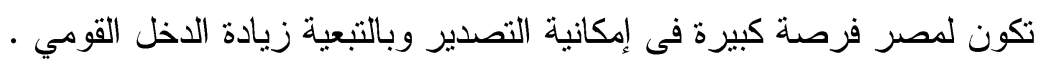

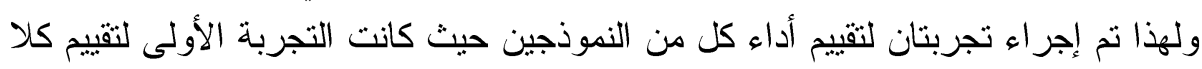

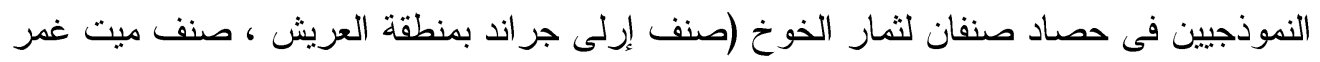
بمنطقة ميت غمر) مقارنة بطرق الحصاد التقليدية المتبعة فى هذه المناطق بينما كانت التجربة الثانية

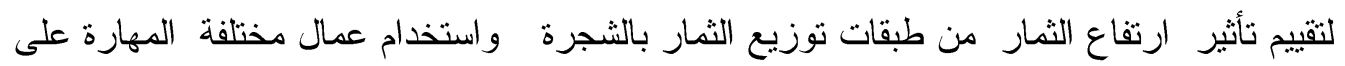

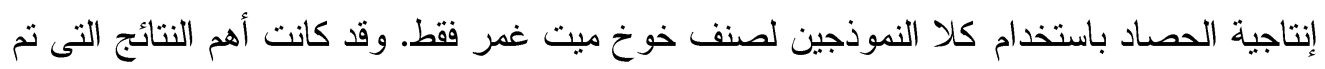
الحصول عليها كما يلى:-

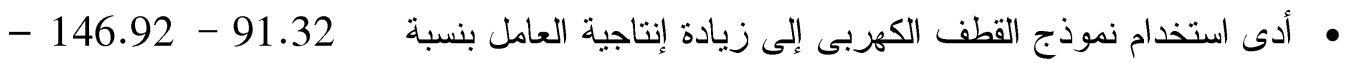

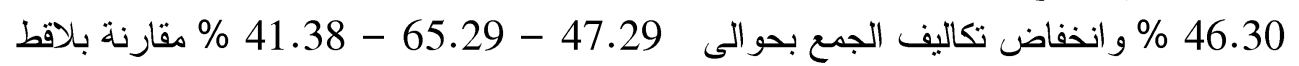

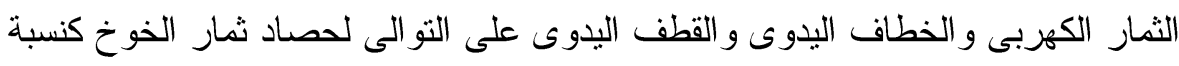

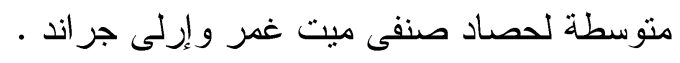

• استخدام نموذج القطف الكهربى لحصاد ثمار الخوخ أعطى أقل نسبة تلف ميكانيكى بالثمار

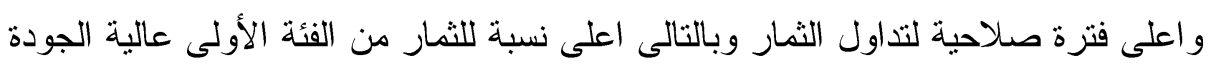

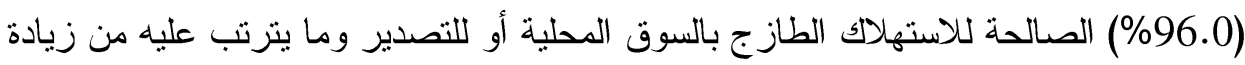

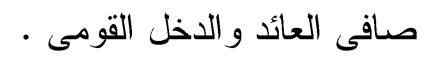
• يوصى الباحثون بالتصنيع المحلى و استخدام نموذج القطف الكهربى لحصاد ثمار الخوخل توفير

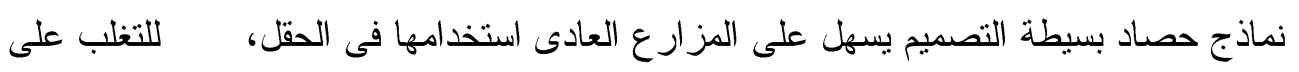

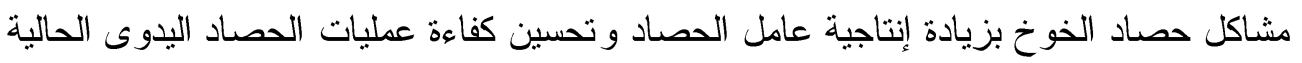

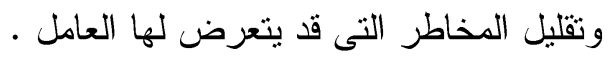

